\title{
Modeling highway projects: The need for Highway Information Modeling (HIM) guideline and information exchange
}

\author{
U. Ertaymaz and G. Atasoy* \\ Middle East Technical University, Department of Civil Engineering, Ankara, Turkey
}

\begin{abstract}
Building Information Modeling (BIM) is one of the latest trends in the construction sector and utilized for modeling, reviewing and analyzing building projects for the last two decades with benefits including visualization, planning, and estimation. BIM provides a well-organized and streamlined approach for building projects; however, its application for highway projects has been scarce. Progressing requirements, increasing number of stakeholders, integrated design solutions, expanding model uses and rapid evolution of construction sector lead to the implementation and integration of new technologies and applications. Thus, Highway Information Modeling (HIM) becomes a necessity to facilitate design, quantity take-off, simulation, clash detection and many other uses. However, neither the definitions of the uses nor the platforms to perform such analysis on highway projects throughout their life cycle are sufficient and well defined. Hence, the initial objective of this study is to provide an overview of information necessary for defining HIM concepts and developing HIM guidelines. The secondary objective is to present a case study to illustrate the elementary interoperability capabilities of current tools. Interoperability seeks information exchange requirements and data loss in physical, functional and semantic properties of elements.
\end{abstract}

\section{Keywords}

Building Information Modeling; BIM uses; Guidelines; Information exchange; Highway Information Modeling; HIM uses

Received: 20 December 2018; Accepted: 14 March 2019

ISSN: 2630-5771 (online) @ 2019 Golden Light Publishing All rights reserved.

\section{Introduction}

As being one of the latest trends in the construction sector, Building Information Modeling (BIM) has been one of the main focuses of both academic studies and sector applications. Throughout the years, many definitions of BIM have been proposed by researchers and organizations. According to National BIM Standard Fact Sheet [1], "BIM is the digital representation of physical and functional data which is also a shared knowledge resource for information about a facility forming a reliable basis for decisions during its life-cycle; defined as existing from earliest conception to demolition". Associated General Contractors (AGC) Guide to BIM [2] defines BIM as, "Development and use of a computer software model to simulate the construction and operation of a facility". AGC [2] continues by stating that the model that is generated at the end should be in a format that is acceptable to all stakeholders. BIM is one of the main keys to ease the information flow process for stakeholders. Hence, a smooth information exchange between stakeholders, and capturing physical, semantic and functional data using software tools are important

Corresponding author

Email: guzide@metu.edu.tr 
characteristics for BIM implementation. The quality and maturity of BIM implementation have been fostered with the development of standards and guidelines regarding the implementation and execution of BIM.

While BIM has become a common approach for building projects, its application for highway projects, Highway Information Modeling (HIM) is very sparse. Civil Information Modeling (CIM) is the term that has been recently introduced for BIM supported civil infrastructure projects including highways and bridges [4-6]. Academicians and industry practitioners accept the effectiveness of integrating BIM for the integrated management of highways, railways and utilities [20]. Each subdomain of infrastructure contains unique construction elements that should be handled individually. There is no single platform/tool that captures all the requirements for each of these domains; instead, separate concepts are being discussed. For instance, object-oriented modeling extends to Bridge Information Modeling (e.g., BrIM [6]), Railway Infrastructure Information Modeling (e.g., RIIM [7]) and Airport Information Modeling (e.g., AIM [8]). These studies lead to domain-specific tools and in order to increase the success rates of such applications, the introduction of specific guidelines for each fragmented domain is needed. Although highway projects are an integral part of construction projects with a high number of stakeholders, HIM is not well adopted by the industry. Moreover, there is little guidance on what HIM comprises and how the HIM related information can be communicated between the stakeholders. In order to address this problem and to reach the advancements achieved through BIM for the highway projects, HIM related concepts, guidelines, and tools need to be investigated. Hence, the main objective of this study is to explore such HIM related information.

\section{Specifications and guidelines}

To maintain high-quality BIM implementation and communication between project stakeholders; guidelines, standards, and execution plans are needed. Indeed, for the effective communication of project data and stakeholder requirements, many BIM specifications and guidelines have been developed in the last ten years by universities and organizations. Cheng and Lu [3] examined the BIM guidelines developed and used in 14 countries/areas and identified more than 120 guidelines with diversified contents. Because of expectations, regional characteristics, and existing state of BIM establishment, guidelines differ from each other. However, these guidelines mostly address the need for streamlined application of BIM by outlining general goals and uses, Level of Development (LOD), project BIM execution process, and information exchange as key enablers to plan and manage BIM use. Hence, in order to foster streamlined BIM utilization, identification of BIM uses with necessary LODs and providing a platform/ infrastructure with adequate levels of information exchange are essential. Vertical projects may have commonalities with horizontal highway projects; however, existence of significant variations due to the project characteristics and activities, stakeholders, existing systems and utilities, and the status of the information technologies in these sectors need to be acknowledged. Because of such differences, existing guidelines for BIM cannot sufficiently address the highway projects. Hence, there is a need for guidelines that are tailored according to specific needs of highway projects. A limited number of studies and guidelines exist for HIM guidelines including the Department of Transport and Main Roads of State of Queensland [9].

Some contents of BIM guidelines such as planning the goals and roles, and BIM execution process can be adapted to highway projects with ease. For instance, the practice of setting goals (e.g., project performance targets) and developing a new set of roles and responsibilities to pursue a BIM process applies to highway projects in a similar way. However, the contents for formalization of uses, LODs, and data exchange should be customized for project and application specific requirements of highway projects. One of the key determinants of these requirements is the technological readiness in terms of infrastructure 
for proper information exchange. A wide range of design tools including Autodesk Civil 3D and Bentley InRoads exist for highways [10]. Sharing the information is one of the key concepts of BIM; hence, existing tools should be able to transfer the physical, semantic and functional data appropriately so that every stakeholder involved in the project can easily view and analyze the model according to their needs. To sum up, guidelines are needed to effectively implement HIM and efficiently identify, use, and transfer model data. To facilitate the adoption of BIM for highway projects, HIM uses, LOD, and information exchange should be examined. This study explores the current state of necessities of HIM and the interoperability capabilities of existing highway design and BIM tools.

\section{Model uses}

BIM Use is defined as "a method of applying Building Information Modeling during a facility's lifecycle to achieve one or more specific objectives" [11]. There is no consensus on definite nomenclature, scope, and boundaries of model uses; however, numerous studies attempt to standardize the terms and present a generic template for such uses. For instance, BIM Project Execution Planning Guide [12] of the Pennsylvania State University (PSU) identified 25 different BIM uses through case studies and interviews. These 25 uses were presented as a common set of uses for building projects. Due to the variations of the projects, systems, and stakeholders, these uses need to be examined and even re-defined for highway projects. For instance, even though computational fluid mechanics or traffic flow simulation are not identified as BIM uses, such uses should be considered for highway projects.

BIM for Transport and Main Roads Guideline [9] directly adopts all the uses (e.g. engineering analysis, digital fabrication) of PSU BIM guideline with only terminology changes. Cheng et al. [10] states a different set of 15 uses for CIM for four different phases of projects, in which, Phase 1 is 'Conceptual Design', Phase 2 is 'Detailed Design and Documentation', Phase 3 is 'Construction' and
Phase 4 is 'Operation and Maintenance'. When compared, it is observed that majority of the uses (e.g., engineering analysis, cost estimation, site analysis etc.) are common. However, it is noted that a number of uses such as code validation and disaster planning, that could be applied to highway projects are not considered in the latter study. Sankaran [13] approaches the CIM uses from the technology perspective. Three main technologies are classified as 3-D/n-D, Sensing, and Data Management and then CIM uses are represented under these technologies with a total of 21 supporting tools. These 21 tools do not define the uses but rather, they are utilized for the analysis, collecting data for the analysis or sharing data and analysis results. As can be seen, there is no consensus on how to define or classify the HIM uses. Additionally, in order to support the implementation of HIM uses, the capture and communication of physical, semantic and functional characteristics of projects should be ensured. Hence, for a transition into HIM with diversified uses, the definitions of uses and required technological infrastructure need to support each other. For HIM, as it is relatively unfamiliar, it may be better not to limit with existing uses of BIM. Particularly, specific and possibly high value HIM uses should be identified with similar approaches including expert opinions, case studies, and review of literature during the development of the guideline.

\section{Level of development (LOD)}

Similar to model uses, there is no de facto definition or consensus to refer to the granularity of the models and their reliability. BIMForum [4] presents that Level of Detail is how much detail is included (input) to the model elements and Level of Development is the reliability of the model (output) in terms of geometric and semantic information. PAS [22] uses Level of Information (LOI) to refer to non-graphical contents of the model and the USA Institute of Building Documentation [21] uses Level of Accuracy (LoA) to "specify and articulate with clarity, the accuracy and means by which to represent and document existing conditions" in 
models. The variations in the nomenclature bring along variations in the scope and boundaries of the granularity, reliability and accuracy of the models. A streamlined application of BIM necessitates elaboration in LOD in the implementation guidelines. One of the leading studies by BIMForum [14] developed an itemized list of LODs (ranging from LOD100 to LOD 500) for various building elements where the increase in the LOD specifies more detailed geometric representation (e.g., nuts and bolts) and inclusion of semantic information (e.g., materials). Cheng et al. [10] demonstrates that existing industry cases for highway projects utilizing LoD500 exists and such highly detailed models are unnecessary and uneconomical. Hence, the need for LODs that specify highway project related elements/objects and reflect the needs of the sector should be acknowledged. Similar to LOD progression presented by BIMForum, Cheng et al. [10] proposes LODs for civil infrastructure projects as (i) LOD100: '3D Block Model' including shape and location, (ii) LOD200: 'Generic Elements' for estimating quantities, (iii) LOD300: 'Detailed and Refined Assemblies' for more accurate estimations, (iv) LOD400: 'Construction-level detailed components' for precise simulations, (v) LOD500: 'As-Constructed Model' including every engineering data for various analysis and O\&M. Sankaran and O'Brein [15] evaluates LOD by introducing four types of elements; 'Surface Models', 'Structure Models', 'Traffic Models' and 'Others'. These elements can have low, medium or high degree of information depending on the use. Abdelwahab et al. [16] uses LOD100-400 for modeling of a bridge project where LOD100 is concept design, LOD200 is preliminary design, LOD300 is detailed design and LOD400 is workshop drawings. Stating the need for leveraging the use and requirements of elements/objects for infrastructure projects, Biljecki et al. [23] decomposes LOD and LOI in terms of geometric complexity, dimension, appearance, semantic, presence and attributes. Another component that should be included into the efforts for standardizing the content and definitions of model granularity for highway projects, is the LOA for existing infrastructure. USIBD [21] proposes five-level LOA ranging from $0-1 \mathrm{~mm}$ to $5 \mathrm{~cm}$-user defined scales ranges to represent the amount of deformation in existing buildings and suggests specific LOA levels of substructure regarding heritage applications. However, the amounts of deformations need to be tailored according to the elements and performance criteria of highway projects.

While some of the studies evaluate LOD as element specific, others focus on the phases of the whole life-cycle of the project. At this point, it might be useful to evaluate LOD in the light of both elements and phases to form a de facto LOD definition according to the intended model use. Most studies focus on the construction stage as HIM is still immature, but this might slow down the evolution of the process. As Ergen and Alshorafa [17] states, the definition of LOD for the entire project is inefficient and time-consuming. The structure of LOD should be formed for each element from block representation to the final product to make all possible uses available when needed. Thus, LOD should be presented according to needs of the intended use. For traffic simulation, the sublayers of the highway might not be represented. However, if load analysis depending on time and traffic passing on the highway is required, the layers should be modeled. For specific uses, the information requirements should be identified and for HIM, these requirements are yet to be determined. While the categories of levels help direct the use of LOD for highway projects, parameters and objects need to be tailored according to the characteristics of the highway projects. In the end, the required physical, functional and semantic data should be within the sufficient degree of information.

\section{Information exchange}

One of the strengths of BIM is the effective representation and communication of project data between stakeholders. Besides the requirements of BIM authoring environment, additional information requirements are introduced with the 
utilization of review and analysis tools. A key concern for supporting multiple model uses is to improve the communication of data within such tools. According to PSU BIM Implementation Guideline [12], deciding on the potential information exchange, information requirements must be identified and when the output is not compatible with the input of upcoming steps it becomes a major problem, as the success of a BIM use is dependent on the accomplished deliverable acquired in the previous phases. For the information exchange of BIMs, Industry Foundation Class (IFC) is the most commonly used file format. However, currently IFC is limited in supporting infrastructure projects and a number of organizational and academic studies are attempting to provide extensions to support such projects [18]. For BIM itself interoperability is an ongoing issue; nonetheless, in relation to BIM for highway, it turns into a bigger challenge. Neutral formats, eXtensible Markup Language (XML), LandXML, and ontologies are utilized but they are still insufficient to address the life-cycle information requirements of horizontal projects [19]. Standardizing the information attributes that are common to highway projects and adapting the workflows can facilitate the adoption of HIM in the sector. Currently no simple data exchange format, plug-in or a converter that enables interoperability between building and highway related tools exist. Building upon the existing studies, to facilitate the standardization and adoption of HIM, the extent to which BIM tools can support highway projects need to be empirically analyzed. Identified gaps can help develop articulated information exchange formats or guidelines outlining the communication of information for the design, asset management and data exchange (input-output compatibility for supporting different model uses) purposes.

\section{Case study}

In order to assess the current state of existing tools in terms of communicating physical, semantic and functional data, a small scaled evaluation is performed in this study. Initially, a small but representative highway project which is given in
Fig. 1, is modeled in Bentley InRoads, using an existing digital terrain model. In addition to physical information, semantic and functional information is also modeled. Indeed, using a dtm file with the terrain model, the alignments, profile, cross section, functional classification and material information of the highway is modeled in the design tool. Then, in order to check the interoperability between the highway and building-oriented tools, project is exchanged within Highway design tools (\#1: Autodesk Civil 3D, \#2: Bentley OpenRoads), BIM autoring tool (Autodesk Revit) and BIM analysis tool for quantity takeoff purposes (Nemetschek Allplan). This exploratory and elementary evaluation of the tools is summarized in Table 1, focusing on two main aspects: the extent of remodeling requirements and degree of physical and semantic data loss.

When the project is imported to BIM authoring tool, the model was imported as a single object albeit including millions of contours, triangles, and highway elements. Due to the high number of elements, this single object could not be exploded, which is the separation of merged elements. Additionally, the existing coordinate system shifted as can be seen in Fig. 2a. The use of local vs global coordinate systems in the building vs highway projects was the main cause of this issue. Since the single object was not usable, visualization and modification capabilities of transferred information could not be performed. After that, the BIM analysis tool was tested for interoperability. The tool includes a direct import option from the main highway design tool. The BIM analysis tool (see Fig. $2 b$ ) only showed the 2D model of the highway with the physical information, without the semantic data, functional data and the terrain model.

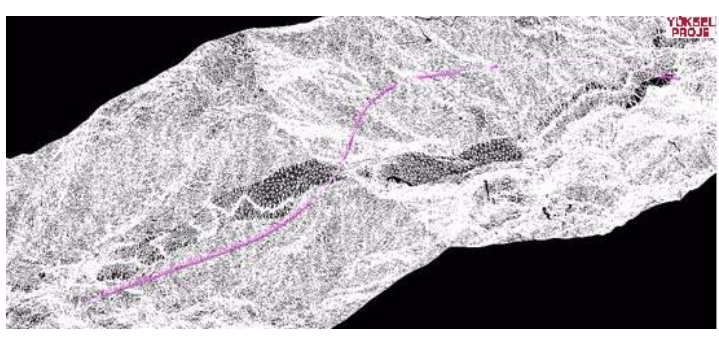

Fig. 1. Project of Modeled Highway in Main Highway Design Tool 
Then, LandXML and .dtm formats were used to import the terrain but both formats were unsuccessful.

Table 1. Used tools, import formats and capabilities

\begin{tabular}{|c|c|c|c|c|}
\hline Tools & $\begin{array}{l}\text { Used } \\
\text { Import/ } \\
\text { Export } \\
\text { Format }\end{array}$ & $\begin{array}{c}\text { Visualize } \\
\text { Physical, } \\
\text { Semantic, } \\
\text { Functional } \\
\text { Data }\end{array}$ & $\begin{array}{c}\text { Edit/ } \\
\text { Modify }\end{array}$ & Problems \\
\hline $\begin{array}{c}\text { BIM } \\
\text { authoring } \\
\text { tool }\end{array}$ & dwg & $\begin{array}{c}\text { Limited } \\
\text { Physical } \\
\text { No Semantic } \\
\text { No Functional }\end{array}$ & $x$ & $\begin{array}{l}\text { Physical } \\
\text { Distortion } \\
\text { and } \\
\text { Changed } \\
\text { Element } \\
\text { Information }\end{array}$ \\
\hline $\begin{array}{c}\text { BIM } \\
\text { analysis } \\
\text { tool }\end{array}$ & .dgn & $\begin{array}{c}\text { Limited } \\
\text { Physical } \\
\text { No Semantic } \\
\text { No Functional }\end{array}$ & $x$ & $\begin{array}{l}\text { Physical } \\
\text { Information } \\
\text { Loss }\end{array}$ \\
\hline $\begin{array}{l}\text { Highway } \\
\text { design } \\
\text { tool } 1\end{array}$ & dwg & $\begin{array}{c}\text { Existing } \\
\text { Physical } \\
\text { No Semantic } \\
\text { No Functional }\end{array}$ & $\checkmark$ & $\begin{array}{l}\text { Engineering } \\
\text { Information } \\
\text { Loss }\end{array}$ \\
\hline $\begin{array}{l}\text { Highway } \\
\text { design } \\
\text { tool } 2\end{array}$ & .dgn & $\begin{array}{c}\text { Existing } \\
\text { Physical } \\
\text { Existing } \\
\text { Semantic } \\
\text { No Functional }\end{array}$ & $x$ & $\begin{array}{l}\text { Imported } \\
\text { Read-Only }\end{array}$ \\
\hline
\end{tabular}
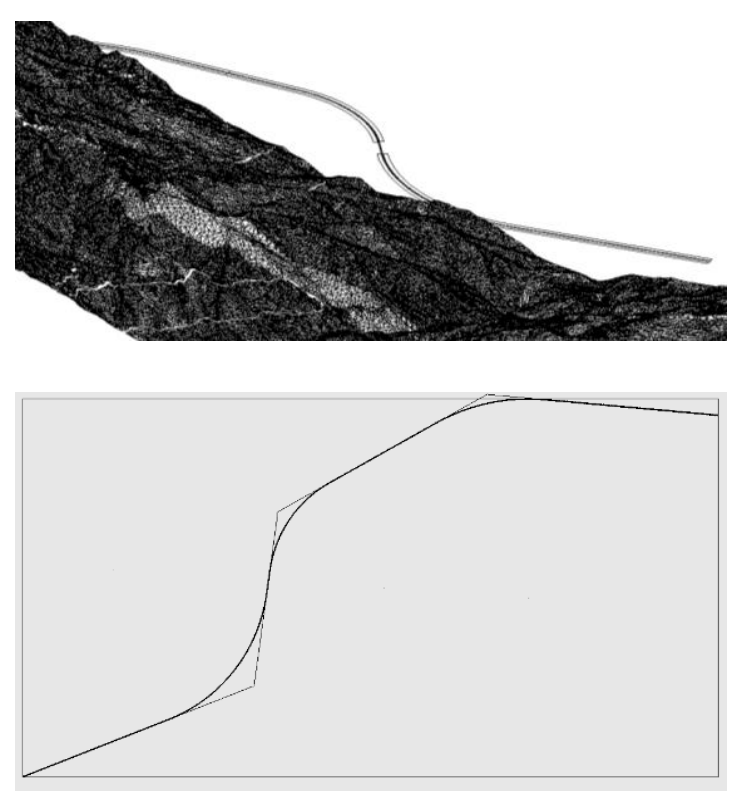

Fig. 2. Imported Project in (a) BIM authoring tool and (b) Analysis tool
As the third tool, the highway design tool 1 that has the same scope as the main highway design tool was used. The 3D model could be imported using .dgn format with physical and surface information. However, the model was lacking semantic data, alignment of the roads and analysis could not be performed. Finally, the project was imported to highway design tool 2. It was successfully imported in terms of geometry and surface information. However, functional data was not transferred and the project could only be opened as read-only. In the end, new exports are gathered from every tool to try roundtrip data exchange. As the tools were not able to read the data appropriately, the lacked data was lost when imported back to origin tool.

The lack of sufficient IFC and XML foundations for highway projects was one of the motivations of this research to observe and test degree of information loss. However, this exploratory degree of information loss test turned out to be an elementary import/export test using prominent tools. A common model use (quantity take-off) could not be performed without remodeling due to the failure of data transfer. Hence, it is observed that the default/ simple workflow of data exchange between aforementioned tools does not support the $\mathrm{BIM} / \mathrm{HIM}$ integration. The lack of repetition in this case study through the use of multiple models with various contents and various tools is acknowledged. The ambiguity in the amount of data loss in case different highway projects are modeled using different tools is required to be addressed with additional well-defined testbed setups. In other words, further testing is required to identify the extent of loss of semantic and functional information (e.g., families, annotations, level of service, and materials), missing objects and geometric misrepresentations/ distortions (e.g., alignment, change of profile, misplacement) regarding objects, surfaces, and utilities for the purposes of visualization and utilization of intended uses. According to PSU BIM Guideline [12], BIM execution planning procedure must include the definition of supporting infrastructure. Hence, for the preparation of HIM guidelines, the current 
exchange capabilities of tools should be considered and the interoperability issues need to be identified. Similar to BIM applications, there is no single standard that fits for all HIM applications. However, generic templates should be developed highlighting the differences in the possible application areas. Hence, to achieve optimal HIM implementation, such templates/ guidelines can be altered based on the specific needs and characteristics of each project and utilized technological infrastructure. Development of HIM guidelines can lead to addressing such challenges, improvements and enhancements in data formats and tool capabilities and a common data exchange format or data enrichment environments.

\section{Conclusion}

In spite of many benefits offered by BIM, its use for highway projects remains limited. Similarly, despite the widespread attempts to formalize BIM guidelines, there is still a gap in terms of HIM guidelines. One of the barriers for adopting streamlined BIM implementation in highway projects is the challenge to identify and formalize the information and technological requirements needed to support object-oriented project modeling. Firstly, there is no established consensus on the definitions, uses, and LOD of the models. While stakeholder requirements are key to identify product and process specific information, there is a lack of guidelines to outline and formulate the minimum requirements regarding nomenclature, the model uses, content, LOD and platform requirements. Indeed, although it is not advisable to use one common standard for all projects; outlining possible model uses and LODs for each element in each phase of the projects is essential for the development of highly articulated HIM guidelines. Moreover, lack of standardized definitions on the physical, semantic and functional information hinders the communication of project data within various tools to support intended uses. In other words, LOD in accordance with the objectives and uses of the model needs to be coordinated and relevant data exchange needs to be supported for streamlined use of HIM. In this study, a preliminary analysis is performed at the outset for an initial observation of the issues arise due to the lack of a neutral file format to exchange information between BIM and HIM tools. Different tools are used to visualize highway project data, and many problems ranging from physical distortion to loss of engineering information are observed. Highway design tools were able to transfer the physical data but not the semantic and functional data. Neither of the BIM tools could import the elements successfully including the physical data such as coordinates and 3D geometry data. Using the basic import/ export functions of multiple tools, this study pinpoints a number of bottlenecks in the communication of highway models in terms of the existence of data loss and distortion. Further testing is required to measure the degree of data exchange covering a wider range of platforms, model uses, highway projects with different LODs, and approaches other than manual/visual inspection (e.g., extensive adjustment of settings, coding and etc.). The question of to what extend the data exchange formats should lead the sector of software vendors in adding improved capabilities and functionalities should be overcome. Additionally, the need for a common platform or common file exchange format to communicate and analyze both building and highway projects is acknowledged as a future research area. Finally, detailed and highway specific guidelines outlining the model uses, LODs and information exchanges are needed to facilitate the transition into HIM.

\section{References}

[1] National Institure of Building Sciences National BIM Standard Fact Sheet, 2015.

[2] Associated General Contractors Guide. The Contractors' Guide To BIM, 2008.

[3] Cheng JCP, Lu Q (2015) A review of the efforts and roles of the public sector for BIM adoption worldwide. Journal of Information Technology in Construction 20: 442-478.

[4] Chong HY, Lopez R, Wang J, Wang X, Zhao Z (2016). Comparative analysis on the adoption and use of BIM in road infrastructure projects. Journal of Construction Engineering and Management, 32: $1-13$. 
[5] Zanen PPA, Hartmann T, Al-Jibouri SHS, Heijmans HWN (2013). Using 4D CAD to visualize the impacts of highway construction on the public. Automation in Construction 32: 136144.

[6] Marzouk MM, Hisham M. Bridge information modeling in sustainable bridge management. In ICSDC 2011: Integrating Sustainability Practices in the Construction Industry, 2012, pp. 457-466

[7] Moon J, Shim C, Lee K, Kim Y, Son W. Development of railway infrastructure information models based on object-based 3d models. 8th World Congress on Railway Research, 2004, Seoul, Korea.

[8] Skandhakumar N. Integrated access control for smart buildings using building information models. PhD Thesis, Queensland University of Technology, 2014

[9] Department of Transport and Main Roads Building Information Modelling (BIM) for Transport and Main Roads: A guide to enabling BIM on Road Infrastructure Projects. Queensland Government, 2017

[10] Cheng JC, Lu Q, Deng Y (20169 Analytical review and evaluation of civil information modeling. Automation in Construction 67: 31-47.

[11] Kreider RG, Messner JI. The Uses of BIM: Classifying and Selecting BIM Uses, Version 0.9. September, The Pennsylvania State University, University Park, PA, USA. 2013, http://bim.psu.edu.

[12] Computer Integrated Construction Research Program. BIM Project Execution Planning Guide Version 2.0. The Pennsylvania State University, University Park, PA, USA. June 15, 2010

[13] Sankaran B. Civil integrated management for highway infrastructure projects: analyses of trends, specifications, impact, and maturity, $\mathrm{PhD}$ Thesis, The University of Texas at Austin, 2017

[14] BIMForum. Level of development specification. BIM Forum. 2015

[15] Sankaran B, O'Brien WJ. Establishing the level of development (lod) requirements for modeling in highway infrastructure. International Conference on Civil and Building Engineering Informatics (ICCBEI), 2015.

[16] Abdelwahab HT. Intelligent Design (4D, 5D, and beyond) for road design and construction projects: two case studies, In International Road Federation IRF Examiner, 2007.
[17] Ergen E, Alshorafa R. Determining Level of Development (Lod) for Building Information Modeling. 12th International Conference on Advances in Civil Engineering, 2015.

[18] Amann J, Borrmann A, Center LO, Gladbach B. Creating a 3D-BIM-compliant road design based on IFC alignment originating from an OKSTRAaccordant 2D road design using the TUM Open Infra Platform and the OKSTRA class library. Technical University of Munich, Germany, 2015.

[19] Le T, Jeong HD (2016) Interlinking life-cycle data spaces to support decision making in highway asset management. Automation in Construction 64: 5464.

[20] Bradley A, Li H, Lark R, Dunn S (2016) BIM for infrastructure: An overall review and constructor perspective. Automation in Construction 71: 139152.

[21] USIBD. USIBD Level of Accuracy (LOA) Specification Guide v.2. Available at: https://usibd.org/product/level-of-accuracy-loaspecification-version-2-0/ (last accessed December 18, 2018).

[22] PAS 1192-2. Specification for information management for the capital / delivery phase of construction projects using building information modelling, 2013.

[23] Biljecki F, Ledoux H, Stoter J, Zhao J (2014) Formalisation of the level of detail in 3D city modelling. Computers, Environment and Urban Systems 48: 1-15. 